\title{
Letter on "Left ventricular systolic function evaluated by strain echocardiography and relationship with mortality in patients with severe sepsis or septic shock: a systematic review and meta-analysis"
}

\author{
Venu M. Velagapudi ${ }^{*}$ (D) and Dennis A. Tighe $^{2}$ \\ See related research by Sanfilippo et al., https://ccforum.biomedcentral.com/articles/10.1186/s13054-018-2113-y
}

We followed with interest the study by Sanfilippo et al. [1], a meta-analysis of pooled observational studies of severe sepsis and/or septic shock. The authors included 794 patients stratified by survivors/non-survivor and showed that global longitudinal strain (GLS) measurements were strongly associated with survival (standard mean difference (SMD) - 0.26; 95\% confidence interval (CI) $-0.47,-0.04 ; p=0.02$ ).

We bring to your attention the significant inherent variability of GLS measurements in the context of proprietary differences in image acquisition platforms and inter-vendor variability in speckle tracking algorithms.

As the pooled data was comprised of four different vendor platforms, interpretation of pooled results should be done with abundant caution. It is notable that when the authors [1] attempted sensitivity analysis grouping studies by vendors/software, such analysis was deemed not feasible.

We particularly emphasize that GLS standard mean difference (SMD) -0.26 and $95 \%$ confidence interval (CI)

\footnotetext{
*Correspondence: velagapv@gmail.com

${ }^{1}$ Division of Pulmonary and Critical Care Medicine, Yale University School of Medicine, New Haven, CT, USA

Full list of author information is available at the end of the article
}

-0.47 and -0.04 between survivors and non-survivors cited in the study [1] should be interpreted with caution in the context of the existing literature: (a) Absolute difference between vendors for average GLS from the three apical views was up to $3.7 \%$ strain units [2] and (b) inter-vendor 2D speckle tracking software variability limits of agreement range \pm 3 to $\pm 4.5 \%$ in measuring GLS [3]

The pooled standard mean difference was less than known inter-vendor variability.

Furthermore, longitudinal deformation is highest in the endocardium and lowest in the epicardium. Currently, there is insufficient evidence to decide if the endocardial, mid-wall, or full-wall strain is the best choice for clinical use [4].

Although the methodology of meta-analysis is robust, the inherent variations in vendor protocols to measure strain, layer specific nature of strain measurements, patient characteristics, and known technical limitations in acquiring strain measurements limit the generalizability of results of such pooled data.

Another systematic review of GLS in severe sepsis/septic shock [5] which analyzed a total of 455 patients did not combine the data by using meta-analysis methods citing significant methodological and statistical differences between the studies.

Until GLS measurements undergo further standardization in the future as being proposed by European Association of Cardiovascular Imaging (EACVI)-American Society of Echocardiography (ASE) strain standardization task force, this limitation continues to apply to currently available pooled data. 


\section{Authors' response}

\section{Filippo Sanfilippo, Carlos Corredor, Nick Fletcher, Luigi Tritapepe, Ferdinando L. Lorini, Antonio Arcadipane, Antoine Vieillard-Baron and Maurizio Cecconi}

We thank Dr. Velagapudi and Tighe for their interest in our paper and for highlighting one of its limitations [1]. Differences between inter-vendor software for evaluation of global longitudinal strain (GLS) were discussed in our study as one of the issues preventing to draw firm conclusions on our results. However, despite such variabilities, we believe that our results are still valid since the goal of studies included into our meta-analysis was not to give any cutoff value of strain that could differentiate between survivors and non-survivors, but rather to study the link between strain as a continuous value and prognosis.

However, in truth, there are other limitations in this and other meta-analyses in the field of echocardiography $[1,6-8]$. Among these, we believe that the most important one remains the lack of correction for confounding factors because these adjustments were never (or rarely) reported in the original studies included. Therefore, in common with most meta-analyses, our meta-analysis only suggests "associations" without the possibility to draw firm conclusions about "causative" mechanisms between the echocardiographic findings and outcomes. Nonetheless, these meta-analyses have also several advantages; the most important we believe are (1) suggesting directions for further echocardiography research through detection of hypothesis-generating associations and (2) highlighting the need for more structured reporting in the setting of critical care echocardiography research.

On a separate note, the correspondents also discuss in their letter the relevance of a small standardized mean difference (SMD) -0.26 (95\% confidence interval $-0.47,-0.04)$ in the context of the already mentioned inter-vendor differences. It should be noted that, even if SMD does not correct for the variability between softwares, the Cochrane Handbook states that SMD is used in a meta-analysis when studies assess the same outcome but measure it in a variety of ways (i.e., using different scales). In these circumstances, SMD is necessary to standardize the results of the studies to a uniform scale before they can be combined. The SMD expresses the size of the intervention effect in each study relative to the variability observed in that study [9]. Therefore, the statistical approach we used was the most appropriate to account for the variability of GLS. Furthermore, there are grounds to hypothesize that the use of SMD may have reduced the impact of inter-vendor differences.
More research is needed in critical care echocardiography; meta-analyses of non-randomized studies should not be taken at face value but as a driving force for further well-designed and focused research.

\section{Funding \\ None.}

Availability of data and materials Not applicable.

Authors' contributions

Both authors, VMV and DAT, contributed equally to the manuscript. Both authors read and approved the final manuscript.

Ethics approval and consent to participate

Not applicable

Consent for publication

Both the authors; Venu M. Velagapudi and Dennis A. Tighe consent for publication of manuscript in Critical Care journal.

Competing interests

The authors declare that they have no competing interests.

\section{Publisher's Note}

Springer Nature remains neutral with regard to jurisdictional claims in published maps and institutional affiliations.

\section{Author details}

${ }^{1}$ Division of Pulmonary and Critical Care Medicine, Yale University School of Medicine, New Haven, CT, USA. ²Division of Cardiovascular Medicine,

University of Massachusetts Medical School, Worcester, MA, USA.

Received: 11 December 2018 Accepted: 4 January 2019

Published online: 08 February 2019

\section{References}

1. Sanfilippo F, Corredor C, Fletcher N, Tritapepe L, Lorini FL, Arcadipane A Vieillard-Baron A, Cecconi M. Left ventricular systolic function evaluated by strain echocardiography and relationship with mortality in patients with severe sepsis or septic shock: a systematic review and meta-analysis. Crit Care. 2018;22(1):183.

2. Farsalinos KE, Daraban AM, Unlu S, Thomas JD, Badano LP, Voigt JU. Headto-head comparison of global longitudinal strain measurements among nine different vendors: the EACVI/ASE Inter-Vendor Comparison Study. J Am Soc Echocardiogr. 2015;28(10):1171-81 e1172.

3. Nagata Y, Takeuchi M, Mizukoshi K, Wu VC, Lin FC, Negishi K, Nakatani S, Otsuji $Y$. Intervendor variability of two-dimensional strain using vendorspecific and vendor-independent software. J Am Soc Echocardiogr. 2015; 28(6):630-41.

4. Mirea O, Pagourelias ED, Duchenne J, Bogaert J, Thomas JD, Badano LP, Voigt JU. Force EA-A-IST: variability and reproducibility of segmental longitudinal strain measurement: a report from the EACVI-ASE Strain Standardization Task Force. JACC Cardiovasc Imaging. 2018;11(1):15-24.

5. Vallabhajosyula S, Jentzer JC. Global longitudinal strain using speckletracking echocardiography in sepsis. J Intensive Care Med. 2018: 885066618799636

6. Sanfilippo F, Corredor C, Arcadipane A, Landesberg G, Vieillard-Baron A Cecconi M, Fletcher N. Tissue Doppler assessment of diastolic function and relationship with mortality in critically ill septic patients: a systematic review and meta-analysis. Br J Anaesthesia. 2017;119:583-94. 
7. Sanfilippo F, Corredor C, Fletcher N, Landesberg G, Benedetto U, Foex P, Cecconi M. Diastolic dysfunction and mortality in septic patients: a systematic review and meta-analysis. Intensive Care Med. 2015;14(6):100413. https://doi.org/10.1007/s00134-015-3748-7.

8. Sanfilippo F, Johnson C, Bellavia D, Morsolini M, Romano G, Santonocito C, Centineo L, Pastore F, Pilato M, Arcadipane A. Mitral regurgitation grading in the operating room: a systematic review and meta-analysis comparing preoperative and intraoperative assessments during cardiac surgery. J Cardiothorac Vasc Anesth. 2017;31:1681-91.

9. Cochrane handook - The standardized mean difference. https://handbook-5-1. cochrane.org/chapter_9/9_2_3_2_the_standardized_mean_difference.htm, 